\title{
A User-centered Design Approach to Near Field Communication-based Applications for Children
}

\author{
Mrim Alnfiai \\ Information Technology Department \\ College of Computer Sienese and Information \\ Taif University, Taif, Saudi Arabia
}

\begin{abstract}
There is an abundance of technology targeting children in terms of education, entertainment, and health; however, little research has been conducted on the usability of Near Field Communication (NFC) to create an interactive, digital environment for children easily accessible on a mobile device. NFC technology is a component of Radio Frequency Identification (RFID) technology and is affordable, intuitive, and accessible. The following research evaluates existing NFC applications for children in terms of their ease of use, appropriateness, and areas in need of improvement. Recommendations are provided in visual design, audio enhancements, reward system, and privacy and security concerns. It is concluded that adopting NFC technology in all facets of life will positively benefit the most vulnerable population, children, but first progress toward a user-centered design for this group is required.
\end{abstract}

Keywords-Near Field Communication (NFC); mobile device applications; NFC tags; RFID; early learning; K-12 students; preschool children; educational software; usability; user-centered design

\section{INTRODUCTION}

In modern society, the number of children using smartphone applications and new technologies is increasing. According to a report, children ages 5 to 9 years old spend about 28 minutes online daily, and this time continuously grows [1]. Another study found that $69 \%$ of children, across eight countries, use a smartphone [1]. Yet another study found that "almost 80 per cent of children who access the Internet from smartphones download or use mobile apps" [1]. Children are using a variety of smartphone applications for different purposes, like entertainment, learning, and taking care of their health. Selecting an appropriate program for a child based on his/her age and inclination is an important task, which requires parents and researchers to pay attention to an application's key features. Therefore, developers need to design an application that suits the child's desires, builds his/her skills, and develops his/her confidence. On the contrary, if developers design an inappropriate program, this may negatively affect the child's skills and reduce the child's self-confidence.

Numerous research studies have shown that children do not yet possess the capabilities and knowledge of adults, so they are considered a different group with their characteristics [2], [3], [4]. Thus, it is preferable to study this group's properties individually by taking a user-centered design approach. A variety of applications have been designed to provide services for children, to enhance the quality of their daily lives, and to provide adequate support to promote involvement in the activities designed by developers. However, while various applications have been developed for children, most of them do not encourage the user to explore and interact with their physical environment. This is despite a set of applications and systems already established in the form of NFC technology, which can be more immersive and userfriendly for children.

This paper serves as a review of existing NFC programs in terms of user-centered design for children. Recommendations are proposed to take into consideration the needs of this vulnerable population. The organization is as follows: an explanation of Near Field Communication technology, a review of existing NFC technology targeting children, analysis of the lack of user-centered design concepts in terms of NFC technology for children, a discussion of recommendations for areas of improvement, and concluding thoughts with a look at future research for NFC technology use in children's applications.

\section{NeAR Field Communication TeChnOlogy}

Most new smartphone devices are compatible with Near Field Communication (NFC) technology. NFC is a wireless technology that works at $13.56 \mathrm{MHz}$ and is used for shortdistance connections. It is a small chip used to store data and can be read by smartphone devices enabled with NFC technology. It supports two communication modes to enable two-way interactions, which are the Peer-To-Peer Mode and the Reader/Writer Mode. In the Peer-To-Peer Mode, a user can simply touch two smartphone devices together to establish the connection and share content between devices. In the Reader/Writer Mode, a user can touch an NFC tag with an NFC-compatible smartphone device to read the tag content. A smartphone-enabled with the NFC tag can read the content of a tag placed elsewhere from a $10 \mathrm{~cm}$ distance [5], [36].

NFC technology is a part of Radio Frequency Identification (RFID) technology; both of allow two-way communication. But RFID technology requires a special RFID reader, unlike NFC technology, which uses an NFC-enabled smartphone to read the chip content. NFC allows a short-range wireless information transfer between smartphone devices, thus the interaction between the devices is simply by touch. Therefore, it is a secure transfer, as it prevents other devices from reading the content of the NFC tag from a distance. Other security issues have been identified but are still being addressed by NFC developers. 
The advantages of NFC technology are that it is simple, easy to use, and easy to learn [6], [7]. It is clear how to interact with the NFC, so it does not require a great amount of cognitive load by children [6]. Additionally, other researchers report that it only requires touching the target tag, which is an effortless process to communicate and interact with devices [7], [36]. Another advantage of NFC technology is that it is quick, as it requires only seconds to establish the connection and read the tag content.

\section{RELATED WORK}

Researchers are currently employing NFC features to develop engaging tools for children. NFC technology has been extended to various fields to promote children's engagement in these areas: education, transportation, safety, entertainment, and health care fields [8], [9], [10], [11], [12], [37], [38], [39], [40], [41], [42], [43], [44].

\section{A. Education}

Several applications with the support of NFC technology have been proposed to enhance learning environments for children [8], [9], [10], [11], [12]. For example, some of these applications are used to support youth learning a second language, while others are used to track school attendance and transportation.

1) Learning a foreign language: Sánchez, Cortés, Riekki, and Oja (2011) present two interactive NFC-based applications to improve the experience of learning languages, which are Touch\&Learn Languages and Touch\&Learn Reading [10]. The primary purpose of both applications is to allow children to learn new vocabularies and learn how to read a foreign language. In the Touch\&Learn Languages application, a user touches an NFC tag with their smartphone, and the application shows the related information that is linked to the NFC content. For example, it displays a word and reads it. By doing so, a child can learn a new word and its pronunciation using their physical environment as an interactive setting. In the Touch\&Learn Reading application, the application displays a word and reads it aloud, and the child must touch the corresponding object that is tagged with an NFC tag. If they touch the correct object, the application presents the object image as confirmation.

Similarly, Lorusso et al. (2018) developed an application that reads the content of NFC tags. The tags are attached to small, touchable samples of objects like plastic animals and toys [11]. The purpose of the application is to enrich the vocabulary and conceptual networks for children with language impairments. The application was tested by kindergarten-age children, and the study results indicated this application is a valuable, engaging learning tool. It also speeds up the learning process, as it makes learning engaging and enjoyable.

Sánchez, Riekki, Rousu, and Pirttikangas (2008) propose another NFC-based interactive application, which is called Touch\&Share [13]. The application uses NFC technology to store information about an object or an animal within a museum. This information stored can be audio files, videos, or text documents to enhance learning. In this application, a user touches a tag that is attached to an item in the museum, and the application provides additional information about the touched item. This application provides an interactive, learning environment within the museum. The application was tested in the local Zoological Museum, and the NFC tags were attached to stuffed animals so that children could learn more about their habitat and life patterns. The study results show that using NFC technology provides an immersive experience in which children can learn.

2) Attendance supervision: Ervasti, Isomursu, and Kinnula (2009) developed an attendance supervision system with the support of NFC technology. In the system, each student was given an NFC card that has their ID (the child's name) [14]. When students arrive at school, they touch an NFC reader, like a smartphone device, that is located at the class entrance with their NFC cards. At that time, the NFC reader records the student ID, the direction (in or out), and arrival time. Students repeat the same procedure when they leave at the end of the school day. The system allows parents to track their children's' attendance without coming to school by sending an instant message to them. It also improves and secures children's transitions from home to school and vice versa. In addition, it enables students to be independent when traveling between home and school, as well as enhances communication between school and home. Another benefit of the attendance supervision system is that it helps teachers by minimizing responsibilities like marking absences. The critical benefit the school gets from the system is that it discourages absenteeism by informing teachers, administrators, and parents of a child's absence in real-time, allowing for immediate intervention. The system was tested in a school by teachers, Grade 1 students, and parents. They report that it has made a marked difference in attendance as well as received a positive adoption rate and provided improvements in the school's daily routine. However, some technical concerns have been reported about the system, which are privacy and security issues such as protecting student information including name, location, and arrival and departure time.

3) Transportation: Rengaraj and Bijlani (2016) presented a child security and monitoring model with NFC/RFID technology and a smartphone device to track child activity and ensure safety [15]. The system is a web-portal and Androidbased mobile application that uses NFC/RFID technology, a smart ID card, and a Child Safety device (CSD). The CSD contains RFID and Global System for Mobile Communications (GSM), or Internet-enabled Wi-Fi or Ethernet cables to communicate with a server. The model provides instant communication between parents, children, and teachers to ensure security in the school, on the bus, and at home by providing a report about the children's activities. The solution was evaluated, and the study outcome shows an acceptance of the use of the system for child security at both parenting and school management levels. 
Recently, Bai, Fu, and Yang (2018) proposed an NFCbased system on a smartphone device for children's safety when they are picked up from school. The proposed system allows teachers to monitor children's movements by identifying and ensuring the pick-up person is rightfully in charge of the child to be picked-up [18]. Teachers scan the authorized person's NFC tag and the child's NFC tag, then the system compares the two tags to ensure they match. If they match, the system sends a message to the child's parents, which includes the name and ID of the individual who has already picked up their child. On the other hand, if the comparison does not match, then the system will automatically communicate with the parents to inform them to correct the authorized individual's information. The system was not evaluated. However, there is a need to add warning functions if the child is absent or they are not at the correct pick-up place.

4) Pervasive learning system: Ivanov proposed a pervasive learning service with the support of NFC technology that describes the objects that are tagged to assist children in recognizing objects within their physical environment [8]. Children can use the system just by touching the objects around them that are tagged by NFC tags to learn their names and characteristics. The system syncs with the Google App Engine cloud, which stores audio recording information about each object to provide verbal information to children. The service can be used in different learning scenarios such as colors, letters, and numbers, shape recognition, learning foreign languages, and many others. The system was evaluated with 10 children ages 3-8 years-old and the results showed that the system was easy to use, and the interface was accessible for children. Findings also reported that the system can be used as an interactive teaching tool, which allows children to learn in their own environment.

\section{B. Health Care}

Many NFC applications have been developed to automate healthcare services, including health promotion, patients' records, and patients' identification.

1) Nutrition guidance (mHealth): Vazquez-Briseno et al. (2013) introduced a smartphone application with the support of NFC technology and QR codes. It offers nutrition guidance to promote healthy diets for children and prevent obesity [19]. The main page of the application presents three buttons, which are the NFC tag scan button that reads the content of the tag attached to food; the second button, which provides a set of food groups; and the last button, which presents and explains the Eat Well Plate. After scanning the tag, the application displays stars as a motivation method if the child ate correctly. Parents are also informed about their child's food selections. Another important feature in the application is, that if a child eats more than the maximum calorie intake, the child and their parents will receive a warning notification. It has been tested in an elementary school environment, and it was an effective method of minimizing health-related problems.
In 2020, Sutjiredjeki et al. presented a medical measurement application with the support of NFC technology and the IoT (Internet of Things) [16]. The application measures five health parameters, which are height, weight, body temperature, blood oxygen $(\mathrm{SpO} 2)$, and heart rate. The application enhances the examination process and speeds it up, as well as allows better integration and management of the children's health records. The main reason for using NFC technology is to automatically transmit the collected data from different sensors to the NFC-based smartphone devices and the electronic key management system (e-KMS) tags, which in this case is electronic medical records for Indonesian children. Using NFC technology in this application eliminates manual recording and digitizes patient records. The result shows that the proposed system can be used to measure several health parameters quickly, and it minimizes the time spent to examine patients.

\section{Entertainment}

Riekki, Sasin, and Pirttikangas (2008) developed a smartphone game with the support of NFC technology; it is called Touch\&Run [17]. The goal of the application is to improve the learning experience and to encourage children to do physical exercise in teams. The game board is divided into a $4 * 4$ grid, and each grid has an NFC tag, which includes the position of that square on the board and the state of that square in the game. A player and their team must occupy the grid as fast as possible by scanning its NFC tag to encourage communication between team members. The team players touch their phones with each other for a few seconds, which allows the phones to transmit between each other. The Touch\&Run game allows children to learn teamwork skills and cooperation between team members.

In 2019, Chen et al. proposed an interactive gaming application called intelligent SOMA (iSOMA) [20]. It attaches an NFC tag on each side of the iSOMA block to determine and detect the current position and the relative position of other blocks. This way, the application can assist users in checking whether they correctly built the blocks and to quickly assemble iSOMA structures. Using NFC technology in the iSOMA game helps in learning the process of how to build the cube quickly, and it overcomes the limitations of the traditional SOMA cube.

Imanara and Horie (2017) developed a home appliance controller with the support of NFC technology [21]. In their proposal, a child touches an NFC tag attached to a plastic toy that represents a house appliance. In return, the command transfers through a Wi-Fi router and enables the corresponding physical household appliance to operate. The evaluation study indicated this game has the chance to improve children's cognitive development by discovering the relationship between the plastic toy and the actual household appliance.

\section{Research Challenges and ReCommendations}

Several NFC applications and evaluation studies have been conducted to better understand applications intended to assist children in completing varying tasks. Nevertheless, there is a lack of study that discusses and analyzes the usability of NFC applications for children. I analyzed the existing NFC 
applications for children. From a user-centered design perspective, most NFC technologies targeting children are in need improvement to meet children's needs, wants, and desires. As a result, recommendations for improvements to overcome these design challenges are presented. Kraleva (2017) and Kraleva, Kralev and Kostadinova (2016) have highlighted some important factors, which should also be taken into consideration when taking a user-centered design approach to developing an NFC-based application for children [22], [23]. These factors include specifying the targeted age group, following simplified design principles, adding audio effects, ensuring that the application is easy to use and rewards success, and taking into account privacy and security roles.

\section{A. Defining the Target Age Group}

Most, but not all, of the proposed NFC applications stipulate the proposed user's age range and cognitive capabilities. Ibarra (2011) reported that children in between the ages of 2 and 4 years old are not able to concentrate on a digital game, unlike those in the age range between 5 and 6 years old, who can focus on the game's goal and can enjoy the concept behind it [24].

Table I shows which developers of NFC applications determined the target age group in their proposal application. Leaving the target group's age undefined negatively affects the acceptance of the applications among children. As each group has a particular ability and desires, developers need to specify for whom their application is built.

\section{B. Simplified Design}

Most user-centered design studies focused on children encourage developers to simplify the design of an application's interface; it should have limited and large buttons that are labeled clearly to enable children to easily recognize the interface items [25]. Some researchers recommend using different colors to get children's attention and avoid using menus, to prevent confusion. Most of the applications that use NFC technology to target young users follow a simple design, and they apply a set of colors to get children's attention.

\section{Music and Sounds}

Salmon (2009) found that using sound and music promotes children's thinking and improves their learning development [26]. She also recommended that teachers and parents use music to enhance children's learning and cognitive development. However, none of the NFC applications for children evaluated in this research provides musical accompaniment, even though it was found by several studies that using proper sounds for kids' applications makes them better perceived by children [27].

The Nutrition Guidance application developed by Vazquez-Briseno et al. (2013) provides textual alerts and notifications, but this is unsuitable for children [19]. Children who fall in the age range between 2 and 4 years old are not able to read text; thus, text alerts are not appropriate for them. Using multimedia like sound, videos, and pictures to deliver the message is a better method to notify children and keep them interested [19]. After thorough review, it can be concluded that developers failed to take this into consideration as $42 \%$ of the applications studied do not provide visual and aural feedback (as shown in Table I).

\section{Easy Tasks}

Developers should simplify tasks to avoid making children bored, which could cause them to avoid using the application the next time. Most NFC applications studied (92\%) are simple, as they only require children to touch the NFC tags with their NFC-enabled mobile device, without any need to input text; meaning, these applications are overwhelmingly suitable for young children, as they do not require typing any content to interact with the application interface. The application not utilizing easy tasks is the Touch\&Run.

TABLE I. NFC APPLICATIONS FOR CHILDREN BASED ON DESIGN PRINCIPLE

\begin{tabular}{|c|c|c|c|c|c|c|c|c|c|}
\hline \multirow[b]{2}{*}{ Applications } & \multicolumn{9}{|l|}{ Features } \\
\hline & 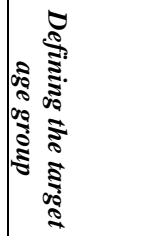 & 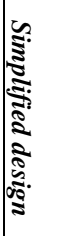 & 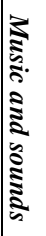 & 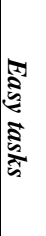 & ॠ.ं. & ב: & 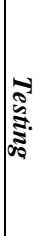 & : & 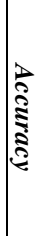 \\
\hline $\begin{array}{l}\text { Touch\&Lear } \\
\text { n Reading } \\
\text { (2011) }\end{array}$ & $\begin{array}{l}\text { Undefine } \\
\text { d }\end{array}$ & $\sqrt{ }$ & $\sqrt{ }$ & $\sqrt{ }$ & $\sqrt{ }$ & $x$ & $\sqrt{ }$ & $\sqrt{ }$ & $x$ \\
\hline $\begin{array}{l}\text { Lorusso et al. } \\
\text { [11] }\end{array}$ & $\begin{array}{l}\text { preschool } \\
4-6 \text { years } \\
\text { old }\end{array}$ & $\sqrt{ }$ & $\sqrt{ }$ & $\sqrt{ }$ & $\sqrt{ }$ & $x$ & $\sqrt{ }$ & $\sqrt{ }$ & $x$ \\
\hline $\begin{array}{l}\text { Touch\&Shar } \\
\text { e (2011) }\end{array}$ & $\begin{array}{l}\text { children } \\
9-13 \\
\text { years old }\end{array}$ & $\sqrt{ }$ & $\sqrt{ }$ & $\sqrt{ }$ & $x$ & $x$ & $\sqrt{ }$ & $\sqrt{ }$ & $x$ \\
\hline $\begin{array}{l}\text { Attendance } \\
\text { supervision } \\
\text { system }\end{array}$ & $\begin{array}{l}\text { First } \\
\text { grade, } \\
\text { Special- } \\
\text { need } \\
\text { Class }\end{array}$ & $\sqrt{ }$ & $x$ & $\sqrt{ }$ & $\times$ & $\times$ & $\sqrt{ }$ & $\sqrt{ }$ & $x$ \\
\hline $\begin{array}{l}\text { Monitoring } \\
\text { system [15] }\end{array}$ & $\begin{array}{l}\text { Undefine } \\
\mathrm{d}\end{array}$ & $\sqrt{ }$ & $x$ & $\sqrt{ }$ & $x$ & $\times$ & $\sqrt{ }$ & $\sqrt{ }$ & $\times$ \\
\hline $\begin{array}{l}\text { Pervasive } \\
\text { learning } \\
\text { system [8] }\end{array}$ & $\begin{array}{l}\text { Aged3 -8 } \\
\text { years old }\end{array}$ & $\sqrt{ }$ & $\sqrt{ }$ & $\sqrt{ }$ & $\times$ & $x$ & $\sqrt{ }$ & $\sqrt{ }$ & $\times$ \\
\hline $\begin{array}{l}\text { Children } \\
\text { Picking } \\
\text { system [18] }\end{array}$ & $\begin{array}{l}\text { Undefine } \\
\text { d }\end{array}$ & $\sqrt{ }$ & $x$ & $\sqrt{ }$ & $\times$ & $x$ & $\times$ & $\sqrt{ }$ & $x$ \\
\hline $\begin{array}{l}\text { Nutrition } \\
\text { Guidance } \\
\text { [19] }\end{array}$ & $\begin{array}{l}\text { Children, } \\
\text { adults }\end{array}$ & $\sqrt{ }$ & $x$ & $\sqrt{ }$ & $\sqrt{ }$ & $\times$ & $\sqrt{ }$ & $\sqrt{ }$ & $x$ \\
\hline $\begin{array}{l}\text { A medical } \\
\text { application } \\
{[16]}\end{array}$ & $\begin{array}{l}\text { Aged 1- } \\
12 \\
\text { months }\end{array}$ & $\sqrt{ }$ & $x$ & $\sqrt{ }$ & $x$ & $\times$ & $\sqrt{ }$ & $\sqrt{ }$ & $x$ \\
\hline $\begin{array}{l}\text { Touch\&Run } \\
\text { [17] }\end{array}$ & Preschool & $\sqrt{ }$ & $\sqrt{ }$ & $x$ & $\times$ & $x$ & $\sqrt{ }$ & $\sqrt{ }$ & $\times$ \\
\hline iSOMA [20] & $\begin{array}{l}\text { Undefine } \\
\mathrm{d}\end{array}$ & $\sqrt{ }$ & $\sqrt{ }$ & $\sqrt{ }$ & $x$ & $x$ & $\sqrt{ }$ & $\sqrt{ }$ & $\times$ \\
\hline $\begin{array}{l}\text { Home } \\
\text { appliances' } \\
\text { controller } \\
{[21]}\end{array}$ & $\begin{array}{l}\text { Children } \\
3+\end{array}$ & $\sqrt{ }$ & $\sqrt{ }$ & $\sqrt{ }$ & $x$ & $\sqrt{ }$ & $x$ & $\sqrt{ }$ & $\times$ \\
\hline
\end{tabular}




\section{E. Prizes}

A recent study highlighted that rewarding children improves their accuracy and encourages them to practice efficient engagement [28]. Prizes also encourage children to keep learning and motivate them to continue doing the required tasks. To keep children's attention and make them concentrate more, developers should reward them after completing any task, such as with a pleasant melody, asterisks, or any engaging image [29], [35]. For example, the Touch\&Learn application presents stars on the application interface when a child completes a task correctly [10]. In the NFC-based applications reviewed, only $25 \%$ of the programs used a prize or rewards system.

\section{F. Privacy Policy and Security}

The most important element that developers consider in any smartphone application is security. Researchers mention the importance of preserving the data of children and protecting those under 13 years of age by a privacy policy, to protect them from the electronic world and to keep them safe [30]. The involvement of NFC technology with smartphone technology introduces new potential security issues, such as eavesdropping [31], data corruption [32], and a man-in-themiddle attack [33].

The security concern is critical when it comes to financial transactions, but the NFC technology is considered secure in most other regards because its communication range is very limited. However, children's information, including name, age, education, and location, should be encrypted to protect children's private information and prevent this information from being leaked to unauthorized persons or hackers. To minimize security issues for NFC applications, some developers ask for a login to ensure that only authorized children and their parents can access the application.

As previously references, some NFC applications are built to track children, like the school attendance or transportation program. Tracking children's movements by parents and teachers is a valuable method for child safety, but it can also be a risk when the captured data is not encrypted. Unfortunately, 92\% of the NFC applications reviewed do not address these privacy and security issues and do not encrypt collected data. Thus, these applications need to be refined based on a security perspective and for children's safety.

\section{G. Testing}

Testing is an important part of developing user-centered software. Since the proposed NFC technology is developed for a special group of users, namely children, the applications must be stable and of the highest quality. It is important to involve the end-users in the design and evaluation phase of the application. Most of the NFC applications for children reviewed $(83 \%)$ have been tested by a few children and their parents, and the results indicate the children's acceptance of the NFC technology and its simplicity to learn. However, a large number of NFC applications for children have not yet been verified and evaluated in the real-world environment. After testing the functionality of the application, longitudinal usability studies are necessary to assess the acceptance of the proposed system by children, family members, and teachers.
In addition, the effects of the proposed system on the child's education and skill development must be evaluated. Furthermore, the consequences and disadvantages of the system on the child's behavior must be evaluated for further development, such as the impact of these applications on children's emotions and motivations. Finally, the most critical aspect that needs to be tested in children's applications is that related to security and privacy issues, as there is a serious need to provide a secure and safe technical world for children.

Other studies highlight some important criteria that developers should take into consideration, which are:

\section{H. Usability}

A new interaction method has been introduced once developers began using NFC technology. Several studies indicated that any new interaction method would cause unconsidered usability concerns [34]. Thus, conducting a set of user studies is critical to expose the usability challenges and meet children's capabilities. It is important to identify the application's usability problems from a user-centered design approach. As shown in Table I, all of the NFC applications were tested for usability. They were found to be usable, as most of the application solved a problem and achieved the goal, and they were easy to learn (and easy to remember) how to use. In addition, the NFC applications that were discussed in related works offer appropriate functions so that children can do what they want to do, and they can simply complete their tasks.

\section{Accuracy}

Accuracy is a very important criterion that encourages children to use the developed application several times. However, none of the NFC applications' accuracy has been measured as seen in Table I. Building accurate applications allow children to use the service in a safe environment with straightforward steps. The error rate can be minimized by building a prototype that addresses most of the proposed application functions and having the target group evaluate it to clearly understand the target group's ability. Developers must take into account the accuracy of the information about the child, especially for the NFC applications that are designed for the healthcare field. Then, the accurate information like location, supports the proposed system to provide the wanted service.

\section{DISCUSSION}

The review of existing NFC-based applications targeted to children shows the technology to be a valuable tool for children in various fields including education, health care, and entertainment. It also finds that most of the NFC applications are cost-effective and require little time or investment to accomplish tasks, as they enable the quick capture of the tag content and transfer it just by touch. NFC technology in education plays an important role, as it is not time-consuming to exchange data.

The findings also reveal that NFC technology is suitable for users with low or no technical background, particularly among children. The NFC applications evaluated seek to contribute to the development of children. As these 
applications provide the opportunity for self-study at children's homes these applications enable an accessible interactive learning environment. Considering these findings, the integration of NFC technology and smartphone applications into early childhood education is thought to be of great importance.

However, employing NFC technology to support children's learning and remaining motivated is considered an emerging practice, as currently there is no widespread use of NFC-based applications. Developers need to consider the impact of other factors when designing NFC applications for children to achieve the successful functionality of their programs. These user-centered considerations include targeted age, knowledge and skills level, simplicity and ease of use, NFC tag locations, social influences, accuracy, and design consistency [10].

One of the advantages of NFC technology is that it can be integrated easily with smartphone applications, and it is usable and easy to use and learn; thus, children can use NFC-based applications with no need for training or support. Another advantage is that all of the NFC-based applications evaluated use a simple design, so children become familiar with the technology and learn how to use it in a short time. However, these NFC-based applications do not meet all inherent children's needs as $42 \%$ of those applications reviewed do not consist of music or sound to attract a user's attention. In addition, $75 \%$ of the applications studied need to provide some engagement or rewarding methods, like showing stars or providing clapping sounds after achieving a task [29].

Another limitation is that the accuracy of the NFC-based applications mentioned has not been evaluated, which is important to minimize the rate of error and minimize their effect, especially in applications that track children's locations. It is very important to improve these tracking and monitoring applications by addressing privacy and security issues, to protect children's information, and to provide a secure digital space for children. There is also a need to implement security protocols when using NFC technology, to secure the data exchange of children's information.

In the future, there is a need to improve NFC-based applications targeting children be implementing a usercentered design approach.

\section{A. Strengths and Limitations}

NFC technology has been used for various applications and it has proved successful in most cases. NFC is used to improve user interaction, as it can afford children the ability to identify the objects around them while encouraging them to do physical activity and share knowledge quickly with others. NFC-based applications has positive qualities that enables it to be effective in many fields and to become increasingly popular due to its high efficiency, low cost, convenience, interaction technique, high reliability, and ability to integrate with smartphones [1], [8], [21], [26], [31].

Another advantage of this technology is that the shape of NFC tags can be customized. Moreover, NFC tags can be used anywhere, because they are waterproof. In addition, the time needed to read the NFC tag content is short. Thus, most of the applications that use NCF technology are simple and efficient. However, as previously noted, it is vulnerable to attack by hackers. Most of the discussed NFC applications for children (92\%) do not address a privacy policy or a particular method to secure children's and parents' information.

\section{CONCLUSION}

By exploring NFC applications, children can use NFC technology to leverage and enhance learning, communication, entertainment, and healthcare. The adoption of NFC technology in schools, hospitals, and the home allows children to positively interact with their surroundings and actively learn while doing physical activities.

The programs developed using NFC technology were studied based on the effective design principles for children and the design criteria for mobile programs in general. Implementing this user-centered design approach, results indicate that some NFC applications have many strengths, which are taking into account the capabilities of the end-users and their age; ease of use; and using some media, such as pictures and sound, to reflect the program's reaction to the child's behavior. However, some of these applications missed important criteria, including adding sound or rewarding children after completing the required tasks. In addition, developers of smartphone applications that use NFC technology need to take into account the privacy of children and increase the protection of personal information and program content, as well address the urgent need to increase the accuracy of data presented by NFC applications. Thus, there is a serious need to improve applications that use NFC technology targeting children, as it is considered an enabler technology that creates usable and easy-to-learn interactive environments for children in the fields of learning, communication, entertainment, and healthcare. Otherwise, it is a missed opportunity.

\section{REFERENCES}

[1] Gutnick, A. Robb, M. L. Takeuchi, J. Kotler, L. Bernstein, and M. Levine. Always connected: The new digital media habits of young children. The Joan Ganz Cooney Center at Sesame Workshop, 2011.

[2] Alnfiai, M., Sampalli, S., \& MacKay, B. (2016). VirtualEyez: Developing NFC technology to enable the visually impaired to shop independently. International Journal of Electrical and Computer Systems (IJECS),1-13. DOI: 10.11159/ijecs.2016.001.

[3] Butler, J. R., \& Nelson, N. L. (2020). Children overclaim more knowledge than adults do, but for different reasons. Journal of Experimental Child Psychology, 201.https://doi-org.sdl.idm.oclc.org/ 10.1016/j.jecp.2020.104969.

[4] Du, Y., Clark, J. E., Valentini, N. C., Kim, M. J., \& Whitall, J. (n.d.). Children and adults both learn motor sequences quickly, but do so differently. Frontiers in Psychology, 8(FEB). https://doi-org.sdl.idm. oclc.org/10.3389/fpsyg.2017.00158.

[5] Nikitin, P. V. Rao K. V. S. and Lazar, S. (2007). An Overview of Near Field UHF RFID. IEEE International Conference on RFID, Grapevine, TX, 2007, pp. 167-174, doi: 10.1109/RFID.2007.346165.

[6] Rukzio, E., Leichtenstern, K., Callaghan, V., Schmidt, A., Holleis, P., \& Chin, J. (2006). An experimental comparison of physical mobile interaction techniques: Touching, pointing and scanning. Proceedings of the 8th International Conference on Ubiquitous Computing (UbiComp 2006: Ubiquitous Computing). Springer. doi: 10.1007/11853565_6.

[7] Välkkynen, P., Niemelä, M., \& Tuomisto, T. (2006). Evaluating touching and pointing with a mobile terminal for physical browsing. Proceedings of the 4th Nordic Conference on Human-Computer Interaction (NordiCHI '06). Association for Computing Machinery, 
New York, NY, USA, 28-37. DOI:https://doi.org/10.1145/1182475.118 2479.

[8] Vanov, R. (2013). NFC-based pervasive learning service for children. In Proceedings of the 14th International Conference on Computer Systems and Technologies (CompSysTech '13) (pp. 329-336). Association for Computing Machinery, New York, NY, United States. DOI:https://doiorg.sdl.idm.oclc.org/10.1145/2516775.2516804.

[9] Emilia Biffi, Peter Taddeo,Maria Luisa Lorusso, and Gianluigi Reni. 2014. NFC-based application with educational purposes. In Proceedings of the 8th International Conference on Pervasive Computing Technologies for Healthcare, 370-372. Doi: 10.4108/icst.pervasivehealth .2014.255350.

[10] Sánchez, I., Cortés, M., Riekki, J., \& Oja, M. (2011). NFC-based interactive learning environments for children. In Proceedings of the 10th International Conference on Interaction Design and Children (IDC '11). Association for Computing Machinery, New York, NY, USA, 205208. DOI:https://doi.org/10.1145/1999030.1999062.

[11] Lorusso ML, Biffi E, Molteni M, Reni G. (2018). Exploring the learnability and usability of a near field communication-based application for semantic enrichment in children with language disorders. Assist Technol. 2018;30(1):39-50. doi: 10.1080/10400435.2016.125 3046. Epub 2017 Feb 13. PMID: 28632018.

[12] Kim, K., Jeong, S., Kim, W., Jeon, Y., Kim, K., \& Hong, J. (2017). Design of small mobile robot remotely controlled by an android operating system via bluetooth and NFC communication. 2017 14th International Conference on Ubiquitous Robots and Ambient Intelligence (URAI). Jeju, South Korea. doi: 10.1109/URAI.2017.799 2864.

[13] Sánchez, I., Riekki, J., Rousu, J., \& Pirttikangas, S. (2008).Touch \& Share: RFID based ubiquitous file containers. In Proceedings of the 7th International Conference on Mobile and Ubiquitous Multimedia (MUM '08). Association for Computing Machinery, New York, NY, USA, 5763. DOI:https://doi.org/10.1145/1543137.1543148.

[14] Ervasti, M., Isomursu, M., \& Kinnula, M. (2009). Experiences from NFC supported school attendance supervision for children. 2009 Third International Conference on Mobile Ubiquitous Computing, Systems, Services and Technologies. Sliema, Malta. doi: 10.1109/UBICOMM. 2009.9.

[15] Vinoth Rengaraj and Kamal Bijlani. (2016). A Study and Implementation of Smart ID Card with M-Learning and Child security, 2nd International Conference on Applied and Theoretical Computing and Communication Technology (iCATccT), July 2016, pp. 305-311.

[16] Sutjiredjeki, Ediana \& Basjaruddin, N \& Fajrin, Diki \& Noor, F. (2020). Development of NFC and IoT-enabled measurement devices for improving health care delivery of Indonesian children. Journal of Physics: Conference Series. 1450. 012072. 10.1088/1742-6596/1450/1/ 012072.

[17] Riekki, J., Sasin, S., \& Pirttikangas, S. (2008). Touchnrun: An RFIDbased distributed board game motivating to move. Poster Proc. Persuasive Technology (Persuasive 2008), University of Oulu, Department of Information Processing Science, Series A, Research Papers, A42: 34-40.

[18] Bai, Y., Fu, C., \& Yang, J. (2018). Using NFC tags and smartphones to design a reliable mechanism to pick a child up from school. 2018 IEEE International Conference on Consumer Electronics (ICCE).Las Vegas, NV, United States. doi: 10.1109/ICCE.2018.8326205.

[19] VAZQUEZ BRISENO, Mabel et al. mHealth Platform and Architectures to Provide Nutritional Guidance to Children. International Journal of Interactive Mobile Technologies (iJIM), [S.1.], v. 7, n. 4, p. pp. 15-20, oct. 2013. ISSN 1865-7923. doi:http://dx.doi.org/10.3991/ ijim.v7i4.3083.

[20] Chen, C. et al. (2019). Intelligent SOMA interactive gaming system. 2019 IEEE 9th International Conference on Consumer Electronics (ICCE-Berlin). Berlin, Germany. doi: 10.1109/ICCE-Berlin47944.2019. 8966163.

[21] Imanara, S., \& Horie, R. (2017). Implementations of dollhouse-smart house interface: Towards an intuitive household appliance control system for age 3+. 2017 IEEE 6th Global Conference on Consumer Electronics (GCCE). Nagoya, Japan. doi: 10.1109/GCCE.2017.8229321.
[22] Kraleva, R. (2017). Designing an interface for a mobile application based on children's opinion. International Journal of Interactive Mobile Technologies, 11(1), 53-70. https://doi-org.sdl.idm.oclc.org/10.3991/iji m.v11i1.609.

[23] Kraleva, R., Kralev, V., \& Kostadinova, D. (2016). A conceptual design of mobile learning applications for preschool children.ArXiv, abs/1606 .05753 .

[24] Ibarra, K. (2011). Designing apps for kids. UX Magazine. Available at https://uxmag.com/articles/designing-apps-for-kids.

[25] Gelman, D. L. (2014). Design for kids. Digital products for playing and learning. Brooklyn, New York : Rosenfeld Media.

[26] Salmon, Angela. (2010). Using music to promote children's thinking and enhance their literacy development. Early Child Development and Care. 180. 937-945. 10.1080/03004430802550755.

[27] Tikkanen, R., \& Iivari, N. (2011). The Role of Music in the Design Process with Children. Human- Computer Interaction -- INTERACT 2011: 13th IFIP TC 13 International Conference, Lisbon, Portugal. https://doi.org/10.1007/978-3-642-23765-2_21.

[28] Jin, X., Auyeung, B., \& Chevalier, N. (2020). External rewards and positive stimuli promote different cognitive control engagement strategies in children. Developmental Cognitive Neuroscience, 44.

[29] Farrow, C., Belcher, E., Coulthard, H., Thomas, J. M., Lumsden, J., Hakobyan, L., \& Haycraft, E. (2019). Using repeated visual exposure, rewards and modelling in a mobile application to increase vegetable acceptance in children. Appetite, 141. https://doi-org.sdl.idm.oclc.org/ 10.1016/j.appet.2019.104327.

[30] iUbend. (2016). A duide to COPPA and mobile apps. Retrieved from http://www.iubenda.com/blog/guide-coppa-mobile-apps/.

[31] Chattha, N. A. NFC - Vulnerabilities and defense. (2014). Conference on Information Assurance and Cyber Security (CIACS), Rawalpindi, 2014, pp. 35-38, doi: 10.1109/CIACS.2014.6861328.

[32] Nearfieldcommunication.org.(2020). Security concerns with NFC technology. Retrieved from http://www.nearfieldcommunication.org/ nfc-security.html.

[33] Haselsteiner, E., \& Breitfuß, K. (2006). Security in Near Field Communication (NFC) strengths and weaknesses. Retrieved from http://events.iaik.tugraz.at/RFIDSec06/Program/papers/002\%20-\%20Se curity\%20in\%20NFC.pdf.

[34] McNamara, N., \& Kirakowski, J. (2006). Functionality, usability, and user experience: Three areas of concern. Interactions, 13, 26-28. $10.1145 / 1167948.1167972$.

[35] Glatt, S. J. (2020). Initial responsiveness to reward attainment and psychopathology in children and adults: An RDoC study. Psychiatry Research, 289. https://doi-org.sdl.idm.oclc.org/10.1016/j.psychres.2020. 113021.

[36] Coskun, V., Ozdenizci, B., \& Ok, K. (2013). A survey on near field communication (NFC) technology. Wireless Personal Communations, $71,259-294$.

[37] Alnfiai, M., Sampalli, S., MacKay, B. (2016). VirtualEyez: Developing NFC Technology to Enable the Visually Impaired to Shop Independently. Proceedings of the 2nd International Conference on Computer and Information Science and Technology (CIST'16). Ottawa, Canada - May 11 - 12, 2016, Recognized as the Best Paper in the Conference.

[38] Alnfiai, M., Sampalli, S., MacKay, B. (2016). VirtualEyez: Developing NFC Technology to Enable the Visually Impaired to Shop Independently. International Journal of Electrical and Computer Systems (IJECS),1-13. DOI: 10.11159/ijecs.2016.001.

[39] Alnfiai, M., Sampalli, S. (2017). BrailleEnter: A Touch Screen Braille Text Entry Method for the Blind. The 8th International Conference on Ambient Systems, Networks and Technologies (ANT 2017), Procedia, Computer Science.

[40] Alnfiai, M., Sampalli, S. (2017). Social and Communication Apps for the Deaf and Hearing Impaired. International Conference on Computer and Applications (ICCA'17), Dubai, Computer Science.

[41] Alnfiai, M., Sampalli, S. (2017). An Evaluation of BrailleEnter keyboard: An Input Method Based on Braille Patterns on Touchscreen 
Devices. International Conference on Computer and Applications (ICCA'17), Dubai, Computer Science.

[42] Alnfiai, M., Sampalli, S. (2018). BraillePassword: Accessible Web Authentication Technique on Touchscreen Devices. Journal of Ambient Intelligence and Humanized Computing. Springer.

[43] Garrido, P. C., Miraz, G. M., Ruiz, I. L., \& Gomez-Nieto, M. A. (2011). Use of NFC-based pervasive games for encouraging learning and student motivation. In Near Field Communication (NFC), Third International Workshop on Near Field Communication, Hagenberg, 2011, pp. 32-37, doi: 10.1109/NFC.2011.13.

[44] Alan, U. D., \& Birant, D. (2018). Server-Based Intelligent Public Transportation System with NFC. in IEEE Intelligent Transportation Systems Magazine, vol. 10, no. 1, pp. 30-46, Spring 2018, doi: 10.1109/MITS.2017.2776102. 